\title{
ESTABILIDADE DE RENDIMENTO DE GRÃOS DE TRIGO NA REGIÑO DO VALE DO PARANAPANEMA, SP ( $\left.{ }^{1}\right)$
}

\author{
ANTONIO WILSON PENTEADO FERREIRA FILHO $(2,3)$, CARLOS EDUARDO \\ DE OLIVEIRA CAMARGO $(2,3)$, JOĀO CARLOS FELICIO $(2,3)$ \\ ○ JOSÉ GUILHERME DE FREITAS $(2,3)$
}

\begin{abstract}
RESUMO
Para o estudo da estabilidade da produçāo de grāos, utilizaram-se onze genótipos de trigo (Triticum aestivum L.) em dezesseis ambientes da regiăo do Vale do Paranapanema, SP, em 1984-87. Através do modelo desenvolvido por Eberhart \& Russel, toi possivel detectar variabilidade entre os genótipos estudados em relaçąo aos ambientes considerados. O melhor ambiente foi o de Pedrinhas Paulista, em 1985,e o pior, o de Assis, em 1984. O genótipo BH-1146 foi o mais estável e apresentou o maior rendimento de grăos. Os cultivares Alondra-4546, IAC-5 e Paraguay 281 mostraram adaptaçăo especffica para bons ambientes. Esse modelo permitiu identificar os melhores ambientes e as variedades mais estáveis na recomendaçăo de cultivares de trigo, justificando a sua utilização para o Vale do Paranapanema.
\end{abstract}

Termos de Indexaçấo: trigo, cultivares, grâos, estabilidade de rendimento e rendimento médio; coeficiente de regressáo, indice ambiental.

\section{ABSTRACT \\ STABILITY OF GRAIN YIELD ON WHEAT GENOTYPES AT THE PARANAPANEMA VALLEY, STATE OF SĀO PAULO, BRAZIL}

The yield stability of eleven wheat genotypes was studied on sixteen localities with different environmental conditions at the Paranapanema Valley State of São Paulo, in the period 1984-87. Using Eberhart \&

(1) Com verba suplementar do Convênio do Trigo entre as Cooperativas dos Produtores Rurais do Vale ¿o Paranapanema e a Secretaria da Agricultura - IAC. Apresentado na XV Reuniáo Nacional de Pesquisa de Trigo ém Passo Fundo - RS, de 19 a 23 de setembro de 1988. Recebido para publicaçăo em 6 de outubro de 1989 e aceito em 13 de março de 1990.

(2) Seçấo de Arroz e Cereais de Inverno, Institựto Agronómico (IAC), Caixa Postal 28, 13001 Campinas, SP.

(3) Com bolsa de pesquisa do CNPq. 
Russer's model it was possible to detect variability among the genotypes considering the different localities. Pedrinhas Paulista showed to be the best one in 1985 and Assis the worst, in 1984. The genotype BH-1146 was the most stable for all considered environments with the highest yield. The cultivars Alondra-4546, IAC-5 and Paraguay-281 presented adaptation only under favorable growing conditions. The use of this model permitted to identify the best environments and the most stable varieties, justifying its use for wheat cultivar recommendations, on the present study.

Index terms: wheat, cultivars; grain yield stability, average grain yield, environment index.

\section{INTRODUÇÃo}

A exploração comercial intensiva de culturas tornou de fundamental importância a obtenção de altos rendimentos com boa estabilidade. Isso tem acarretado um problema adicional ao melhorista, obrigando-o a selecionar variedades com potencial genético elevado para rendimento de grãos e boa estabilidade diante dos diversos ambientes. O genótipo ideal de trigo seria, pois, aquele que também produzisse altos rendimentos de grãos em qualquer condiçāo ambiental; entretanto, os efeitos genéticos não são independentes dos ambientais, havendo uma interação genótipo $x$ ambiente. Assim, alguns genótipos não têm revelado comportamento satisfatório nos diferentes ambientes, enquanto outros têm mostrado certa estabilidade. As reaçōes dos cultivares aos ambientes podem ser medidas através de parâmetros estatísticos. Genótipos estáveis revelaram baixa interação, enquanto aqueles com alta interação foram considerados instáveis (CARVALHO et al., 1983). Essas respostas dos cultivares aos diferentes ambientes, na maioria das vezes, têm sido lineares, variando de acordo com o ambiente (PLAISTED \& PETERSON, 1959; WRICKE, 1962; FINLAY \& WLKINSON, 1963, e ALLARD \& BRADSHAW, 1964). Desse modo, o maior problema que o pesquisador tem enfrentado é a escolha dos melhores parâmetros para medir a estabilidade fenotipica dos cultivares.

Diversos autores desenvolveram métodos paramétricos para estudar tal estabilidade. FINLAY \& WLKINSON (1963) utilizaram um modelo com dois parâmetros: o primeiro foi a média dos rendimentos de cada genótipo (ȳ) nos diferentes ambientes e, o segundo, o coeficiente de regressão linear (b) de cada genótipo diante dos vários ambientes. EBERHART \& RUSSEL (1966) adicionaram um terceiro parâmetro a esse modelo: desvios da linearidade $=S_{\mathrm{di}}$ (desvio do rendimento de cada genótipo em cada ambiente em relação à linha de regressão desse cultivar em todos os ambientes). Os conceitos de estabilidade desses autores são diferentes. Para os primeiros, o genótipo ideal deveria exibir alto potencial genético para rendimento e um coeficiente de regressão igual a zero $(b=0)$. Já EBERHART \& RUSSEL (1966) apontaram como ideal um genótipo com alta média de rendimento; porém, o coeficiente de regressão deveria ser igual a um 
$(b=1)$ e o desvio de linearidade, igual a zero $\left(S_{d l}=0\right)$. BAKER $(1969)$ empregou a soma dos quadrados da interaçăo genótipo $x$ ambiente, dada na análise da variância como parâmetro. Esse método, porém, não tem sido de grande eficiência, pois, quando os genótipos apresentavam contribuiçōes semelhantes para a soma de quadrados, o parámetro năo detectava diferenças entre eles (CARVALHO et al., 1983). Por outro lado, o parâmetro desenvolvido por BAKER (1969) não deixava claro se a contribuiçăo maior era devida à linearidade ou aos seus desvios.

Outro modelo, desenvolvido por WRICKE (1962), com base em um só parâmetro, denominado ecovalência, levava em conta o efeito do genótipo em determinado ambiente e retirava o efeito ambiental, restando, portanto, 0 valor correspondente ao desvio devido ao efeito da interaçáo genótipo $\mathrm{x}$ ambiente. Assim, os genótipos mais estáveis eram aqueles que apresentavam um valor de ecovalência próximo a zero. CARVALHO (1980), realizando uma análise comparativa entre os parámetros estimativos de estabilidade em trigo, mostraram a semelhança de resultados obtidos pela aplicaçăo dos diversos modelos. Assim sendo, o presente trabalho tem como objetivo determinar a magnitude da interação genótipo $x$ ambiente em variedade de trigo em cultivo no Estado de São Paulo, através do método proposto por EBERHART \& RUSSEL (1966), visando auxiliar nos próximos lançamentos de cultivares de trigo para o Vale do Paranapanema (SP).

\section{MATERIAL E MÉTODOS}

Neste estudo, utilizaram-se os dados de rendimentos de grãos de onze genótipos de trigo, obtidos dos ensaios de cultivares recomendados para a regiāo do Vale do Paranapanema, no período 1984-87, totalizando dezesseis locais distintos.

Em 1984, usaram-se os dados dos ensaios efetuados em Maracaí, Assis, Pedrinhas Paulista e São José das Laranjeiras; em 1985, os dados dos mesmos locais, com exceçāo do de Maracai, que foi substituído pelo de Cruzália; em 1986, os ensaios dos mesmos locais de 1984, com exceção do de Assis, que foi trocado pelo de Cruzália e, em 1987, os dados de rendimento dos experimentos de Maracaí, Cândido Mota, Cruzália e São José das Laranjeiras.

O delineamento estatístico foi o de blocos ao acaso, com quatro repetiçōes. As parcelas foram constituidas de cinco linhas de $5 \mathrm{~m}$ de comprimento, espaçadas de $0,20 \mathrm{~m}$, deixando uma separaçăo lateral de $0,60 \mathrm{~m}$ entre parcelas, com uma área útil de colneita de $5 \mathrm{~m}^{2}$.

A densidade de semeadura variou de 350 a 400 sementes por metro quadrado, encontrando-se, no quadro 1, a genealogia dos onze cultivares testados. 
QUADRO 1. Genealogia das variedades de trigo testadas nos diferentes ambientes de cultivo no Vale do Paranapanema, SP

\begin{tabular}{ll}
\hline Cultivares & \multicolumn{1}{c}{ Genealogia } \\
\hline Alondra 4546 & D 6301/Nainara Weique Red Mace/3/Ciano*2/Chris \\
Anahuac & /I 12300//Lerma Rojo 64/Siete Cerros 66/3/Norin \\
BH-1146 & Ponta Grossa 1//Fronteira/Mentana \\
IAC-5 & Frontana/Kenya 58//Ponta Grossa 1 \\
IAC-17 & lassul//RN 526-63 \\
IAC-18 & BH-1146* 4/S 12 \\
IAC-21 & Siete Cerros 66/C-17 \\
IAC-23 & Pel A 393-65//AC-5 \\
IAC-24 & lassul 51/4/Sonora 64/Yaqui 50 Enano//Gaboto/3/2*Ciano \\
Paraguay 281 & Klein Cometa//Newthatch/Mentana/3/Menkemen/4/Mayo 54 \\
PAT 72247 & Amazonas"S"//Tezanos Pintos Precoz/Sonora 64A
\end{tabular}

Efetuou-se a análise conjunta da variância dos dados de rendimento de grãos dos dezesseis experimentos. A estimativa de estabilidade das onze variedades, nos dezesseis locais considerados, foi calculada de acordo com o modelo desenvolvido por EBERHARD \& RUSSEL (1966), mediante a seguinte fórmula:

$$
Y_{i j}=\mu_{i}+\beta_{i} l_{j}+\delta_{i j}+\Sigma_{i j}
$$

onde:

$Y_{i j}=$ estimativa de estabilidade (média do genótipo i no ambiente j);

$\mu_{\mathrm{ij}}=$ média do genótipo em todos os ambientes;

$\beta_{j}=$ coeficiente de regressão do genótipo i em todos os ambientes;

$\mathrm{l}_{\mathrm{j}}=$ indice ambiental, obtido pela diferença entre o rendimento médio de todos os genótipos no ambiente j com o rendimento médio geral de todos os ambientes;

$\delta_{i j}=$ desvio do genótipo i em relaçāo a sua linha de regressão no ambiente j; $\Sigma_{\mathrm{ij}}=$ resíduo associado à média.

Segundo os autores desse modelo, para revelar estabilidade, um genotipo deverá satisfazer às seguintes condiçōes:

a) a média de rendimento de cada genótipo $\left(\mu_{i}=\frac{\sum_{i} Y_{i j}}{n}\right)$ deverá ser maior do que a das demais variedades nos ambientes considerados;

b) o coeficiente de regressão de cada genótipo $\left(b_{i}\right)$, em face dos diferentes ambientes estudados, deverá ser igual à unidade, ou seja: 
$b_{i}=\frac{\sum_{i} Y_{i j} l_{j}}{\sum_{j} l_{j}^{2}}=1 ;$

c) o desvio de linearidade $\left(s_{\mathrm{di}}\right)$ do rendimento de cada genótipo, em cada ambiente, em relação à linha de regressão desse cultivar em todos os ambientes, deverá ser igual a zero, isto é:

$$
S_{\mathrm{di}}^{2}=\frac{\sum_{\mathbf{i}}^{\Sigma} \begin{array}{c}
\hat{\delta}^{2} \\
\mathrm{ij}
\end{array}}{n-2}-\frac{\mathrm{S}^{2}}{r}=0
$$

onde:

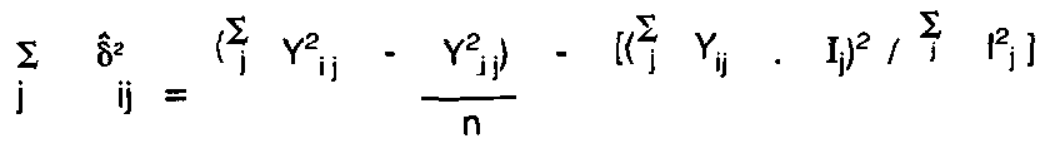

$S^{2}{ }_{e}=$ variância do resíduo;

$r=$ repetiçōes;

$\mathrm{n}=$ número de ambientes.

$O$ índice ambiental $\left(l_{j}\right)$ foi obtido, utilizando-se a seguinte formula:

$$
I_{j}=\frac{\sum_{i} Y_{i j}}{v}-\frac{\sum_{i j} Y_{i j}}{v n} \text {. }
$$

Esse índice revela o comportamento das variedades em todos os ambientes considerados.

\section{RESULTADOS E DISCUSSÃO}

Os resultados da análise conjunta da variância mostraram diferenças altamente significativas para ambientes, genótipos e interaçâo genótipo $x$ ambiente, na manifestação do caráter rendimento de grãos (Quadro 2). A significância para ambientes revelou que os locais considerados apresentaram comportamentos diferenciados, provavelmente em vista das diversidades de temperatura, regime pluviométrico, luminosidade e fertilidade do solo.

O efeito altamente significativo para genótipos mostrou que as variedades utilizadas diferiram quanto ao rendimento. A elevada significancia da intera- 
ção genótipo $x$ ambiente permitiu detectar grande contribuição dos efeitos ambientais na produção dos cultivares.

QUADRO 2. Análise conjunta da variância do rendimento de grăos $(\mathrm{kg} / \mathrm{ha})$ de onze genótipos de trigo testados em dezesseis locais do Vale do Paranapanema, SP, em 1984-87

\begin{tabular}{lrrrr}
\hline Causas de variação & G.L. & \multicolumn{1}{c}{ S.Q. } & \multicolumn{1}{c}{ Q.M. } & \multicolumn{1}{c}{ F } \\
\hline Ambiente (A) & 15 & 334.633 .500 & 2.230 .890 & $9,87^{* *}$ \\
Genótipos (G) & 10 & 11.732 .990 & 1.173 .299 & $5,19^{* *}$ \\
G X A & 150 & 3.388 .570 & 225.904 & $102,14^{* *}$ \\
Residuo & 480 & 1.061 .609 & 2.211 & \\
\hline
\end{tabular}

"* Significativo ao nivel de $1 \%$.

A análise de estabilidade, realizada com os dados obtidos durante quatro anos, dos onze genótipos de trigo nos dezesseis ambientes, mostrou diferenças de respostas para as estimativas dos três parâmetros da equação desenvolvida por EBERHART \& RUSSEL (1966). Através das diferenças significativas, observadas entre as médias de produçōes de grãos, verificou-se variabilidade entre os genótipos, principalmente com relação ao cultivar $\mathrm{BH}-1146$, de origem brasileira, que apresentou o mais alto rendimento em relaçáo aos demais $(1.940 \mathrm{~kg} / \mathrm{ha})$. Por outro lado, a menor produçáo foi verificada para o 'Alondra-4546', originário do México (1.468kg/ha) (Quadro 3).

De acordo com os estudos desenvolvidos por EBERHART \& RUSSEL (1966), um genótipo estável deverá possuir, além de alto potencial genético de rendimento de grãos, um coeficiente de regressão linear igual à unidade $(b=1)$ e a menor variáncia possivel dos desvios da regressäo linear $\left(S d^{2}=0\right)$.

Entre os onze genótipos, o cultivar IAC-18, nacional apresentou um coeficiente de regressão próximo da unidade $(b=1,01)$ com rendimento de grãos (1.858 $\mathrm{kg} / \mathrm{ha})$, acima da média geral $(1.750 \mathrm{~kg} / \mathrm{ha}) ;$ revelou, porém, alto desvio da regressão linear $\left(\mathrm{Sd}^{2}=40.856\right)$ (Quadro 3 ).

O 'IAC-5' apresentou o menor desvio de regressão $\left(S^{2} d=13.190\right)$, mostrando rendimentos pouco superiores à média e o mais alto coeficiente de regressão $(b=1,16)$. 


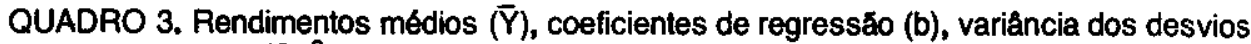
da regressáo $\left(\mathrm{Sd}^{2}\right)$ e quadrado médio dos desvios da regressáo linear (QM) dos onze genótipos de trigo testados nos dezesseis ambientes do Vale do Paranapanema, SP

\begin{tabular}{lcrrr}
\hline Cultivares & $\mathrm{Y}$ & $\mathrm{b}$ & \multicolumn{1}{c}{$\mathrm{Sd}^{2}$} & \multicolumn{1}{c}{$\mathrm{QM}$} \\
\hline & $\mathrm{kg} / \mathrm{ha}$ & & & \\
Alondra-4546 & $1468 \mathrm{~h}$ & 1,10 & 48.719 & $197.088,6$ \\
Anahuac & $1638 \mathrm{~g}$ & 0,92 & 106.976 & $430.117,3$ \\
BH-1146 & $1940 \mathrm{a}$ & 1,09 & 31.843 & $129.586,9$ \\
IAC-5 & $1792 \mathrm{~d}$ & 1,16 & 13.190 & $54.975,4$ \\
IAC-17 & $1866 \mathrm{~b}$ & 0,96 & 62.716 & $253.078,6$ \\
IAC-18 & $1858 \mathrm{~b}$ & 1,01 & 40.856 & $165.637,1$ \\
IAC-21 & $1820 \mathrm{c}$ & 1,04 & 61.362 & $247.660,4$ \\
IAC-23 & $1637 \mathrm{~g}$ & 0,91 & 21.556 & $88.436,0$ \\
IAC-24 & $1763 \mathrm{e}$ & 0,95 & 15.544 & $64.388,7$ \\
Paraguay-281 & $1663 \mathrm{f}$ & 1,11 & 79.542 & $320.380,3$ \\
PAT 72247 & $1804 \mathrm{~cd}$ & 0,73 & 34.704 & $141.029,2$ \\
\hline Media & 1750 & 0,99 & & \\
d.m.s. 5\% & 19 & & & \\
\hline
\end{tabular}

As oscilaçōes das condiçōes climáticas no período, nos diferentes locais, mostraram, através dos índices ambientais - Quadro 4 - obtidos a partir das médias dos rendimentos de grãos dos onze genótipos de trigo, que o melhor ambiente foi o de Pedrinhas Paulista, em 1985: observou-se alto rendimento médio de grăos $(3.288 \mathrm{~kg} / \mathrm{ha})$ e alto índice ambiental $(1.538,24)$. Por outro lado, em 1984, Assis apresentou o menor rendimento médio $(728 \mathrm{~kg} / \mathrm{ha})$, com um indice ambiental de -1.022,30, indicando que esse municlpio apresentou o pior ambiente. Desse modo, a interação dos genótipos com esse ambiente pouco favorável acarretou a baixa média de rendimento, concordando com os trabalhos desenvolvidos por PLAISTED \& PETERSON (1959), WRICKE (1962) e FINLAY \& WLKINSON (1963).

Esses resultados também evidenciam - Quadros 2, 3 e 4 - que a variabilidade foi maior entre os anos e locais do que entre os cultivares.

$A$ análise dos dados do quadro 3 e da figura 1 mostrou valores de $b$ próximos de 1 para o 'IAC-18'; menores que 1 para 'Anahuac', 'IAC-17', 'IAC-23', 'AAC-24' e 'PAT-72247', e maiores que 1 para os genótipos Alondra-4546, $\mathrm{BH}-1146$, IAC-5, IAC-21 e Paraguay-281. 
QUADRO 4. Índices ambientais e médias dos rendimentos de grăos dos onze genótipos de trigo submetidos a dez ambientes no Vale do Paranapanema, SP, em 1984-87

\begin{tabular}{lccc}
\hline Locais & Anos & Rendimentos médios índices Ambientais \\
\hline & & $\mathrm{kg} / \mathrm{ha}$ \\
Assis & 1984 & 728 & $-1022,30$ \\
Pedrinhas Paulista & 1984 & 945 & $-804,48$ \\
Maracal & 1986 & 996 & $-753,48$ \\
Maracaĺ & 1984 & 998 & $-752,12$ \\
São José das Laranjeiras & 1986 & 1247 & $-502,39$ \\
São José das Laranjeiras & 1984 & 1271 & $-478,48$ \\
Pedrinhas Paulista & 1986 & 1490 & $-260,03$ \\
Cruzália & 1985 & 1744 & $-6,12$ \\
Assis & 1985 & 1770 & 20,33 \\
São José das Laranjeiras & 1985 & 1918 & 167,88 \\
Cruzália & 1986 & 2017 & 267,15 \\
Cruzália & 1987 & 2235 & 484,97 \\
Cåndido Mota & 1987 & 2254 & 503,70 \\
São José das Laranjeiras & 1987 & 2541 & 791,15 \\
Maracal & 1987 & 2556 & 805,97 \\
Pedrinhas Paulista & 1985 & 3288 & 1538,24 \\
\hline
\end{tabular}

De acordo com o modelo paramétrico utilizado, o 'BH-1146' apresentou a maior estabilidade, com rendimento maior do que a média geral $(1.750 \mathrm{~kg} / \mathrm{ha}) \mathrm{e}$ um coeficiente de regressão (b) não diferente da unidade (Figura 1), revelando uma linearidade na resposta aos diferentes ambientes. Os genótipos Alondra-4546, IAC-5 e Paraguay-281, diferindo entre si em relação à média de produção e com valores do coeficiente de regressăo iguais ou superiores a 1,10, revelaram uma adaptabilidade especifica para bons ambientes, conforme interpretação de VARELA \& FRANCO (1973). Os cultivares Anahuac, IAC-17, IAC-18, IAC-21, IAC-23 e IAC-24 apresentaram uma adaptação média em relação aos diferentes ambientes, sendo os melhores comportamentos do IAC-17, IAC-18 e IAC-21, com rendimentos de grāos próximos do limite superior de significância em relação ao rendimento médio, e coeficientes de regressão (b) mais próximos da unidade $(1,10<\mathrm{b}>0,9)$. $\mathrm{O}$ 'IAC-24' teve um rendimento próximo ao médio e os cultivares Anahuac e IAC-23 estiveram bem abaixo deste, próximo do limite inferior. 


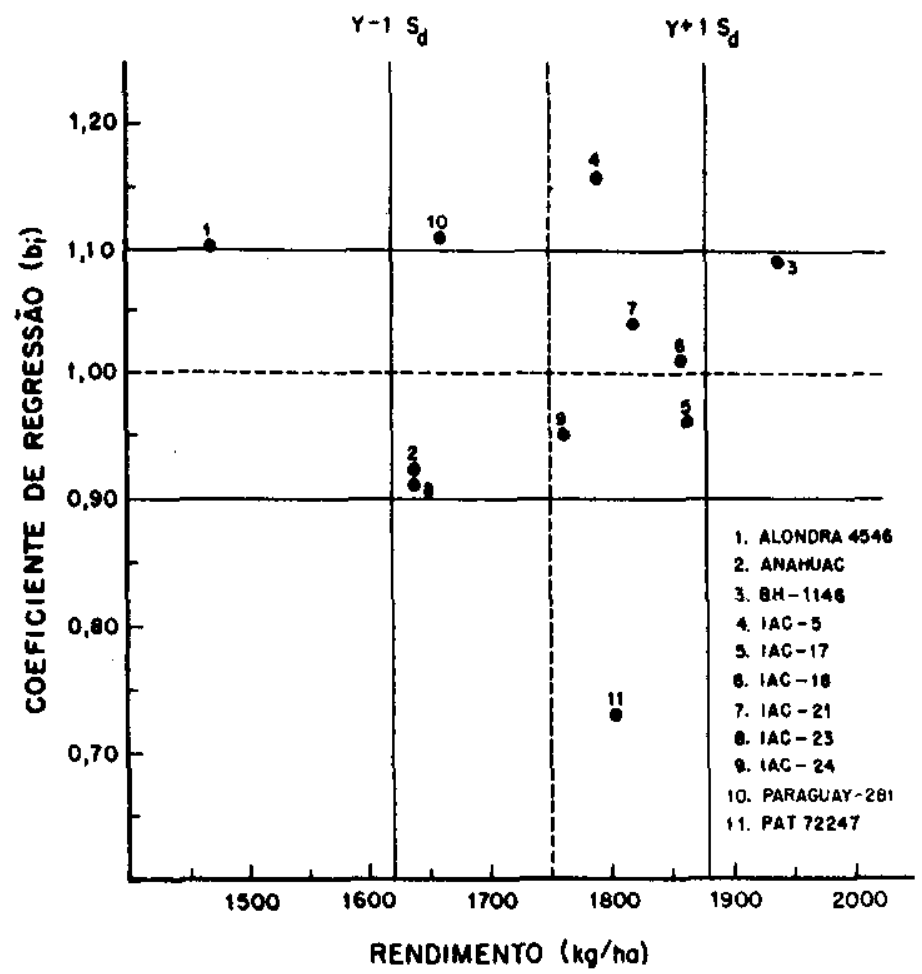

FIGURA 1. Relação entre rendimento médio de grãos e coeficiente de regressão linear dos onze genótipos de trigo testados em dezesseis ambientes no Vale do Paranapanema

O genótipo PAT-72247 apresentou um coeficiente de regressão (b) estatisticamente diferente da unidade $(b<0,90$ ); isso significa que não sofreu alteraçōes muito sensiveis com a variação do ambiente. Por outro lado, apresentando média de produção alta, revelou ser uma variedade específica para ambientes ruins, também conforme interpretação de VARELA \& FRANCO (1973).

Os resultados obtidos nesse estudo concordam com os dados encontrados por VARELA \& FRANCO (1973) e CARVALHO (1980).

\section{CONCLUSÕES}

1. As médias dos rendimentos de grãos revelaram variabilidade entre os genótipos estudados em relação aos diversos ambientes.

2. O melhor ambiente foi o de Pedrinhas Paulista, em 1985, e, o pior, o de Assis, em 1984. 
3. O cultivar $\mathrm{BH}-1146$, de origem nacional, apresentou a maior estabilidade diante dos diversos ambientes, e também revelou o maior rendimento de grãos em relação aos demais.

4. Os genótipos Alondra 4546, IAC-5 e Paraguay-281 apresentaram uma adaptabilidade especifica para bons ambientes.

5. O modelo desenvolvido por EBERHART \& RUSSEL permitiu identificar os melhores ambientes, bem como o comportamento das variedades quanto à estabilidade, o que justifica sua utilizaçāo no estudo da recomendação de variedades de trigo para a região do Vale do Paranapanema, SP.

\section{REFERÊNCIAS BIBLIOGRAFICAS}

ALLARD, R.W. \& FRADSHAW, A.D. Implications of genotype-environment interactions in applied plant breeding. Crop Science, Madison, 4:503-504, 1964.

BAKER, R.J. Genotype-environment interactions in yield of wheat. Canadian Journal of Plant Science, Ottawa, 49:743-751, 1969.

CARVALHO, F.I.F. Uma análise entre diversos parâmetros estimativos de estabilidade em trigo (Triticum aestivum L.). Florianópolis, U.F.S.C.; Fac. Agr., 1980. 57p. Tese (Livre Docência).

—_ ; FEDERIZZI, L.C.; NODARI, R.O. \& STORCK, L. Comparison among stability models in evaluation genotypes. Revista Brasileira de Genética, Ribeirăo Preto, 4:667. $-691,1983$.

EBERHART, S.A. \& RUSSEL, W.A. Stability parameters for comparing varieties. Crop Science, Madison, 6:36-40, 1966.

FINLAY, K.W. \& WILKINSON, G.N. The analysis of adaptation in a plant breeding programme. Australian Journal Agricultural Research, Melbourne, 14:742-754, 1963.

PLAISTED, R.K. \& PETERSON, L.C. A technique for evaluating the ability of selections to yield consistently in different locations and seasons. American Potato Journal, Maine, 36:381-385, 1959.

VARELA, J.D. \& FRANCO, J. Adaptabilidad de variedades promissoras de trigo, 1972. Revista ICA, Bogotá, 1:361-387, 1973.

WRICKE, O. Uber eine Methode zur Erfassung der ökologishen Streubreite in Feldversuchen. Zeitschurift für Pflanzenzüchtung, Berlin, 47:92-96, 1962. 